\title{
Alcohol: another risk factor for diabetic retinopathy?
}

\author{
R J YOUNG, D K MCCULLOCH, R J PRESCOTT, B F CLARKE
}

\begin{abstract}
In a five year prospective study clinical features associated with the development and progress of retinopathy were sought in 296 randomly selected diabetic men aged 20-59. None had ophthalmoscopically detectable retinopathy initially, but during follow up 66 developed the condition (47 background, 10 exudative, 9 proliferative). Linear logistic analyses (two tailed tests) showed that the initial features independently predictive of retinopathy were duration of diabetes, poor glycaemic control, impotence, and-unexpectedlyheavy alcohol consumption. Poor glycaemic control in the interim and proteinuria at review were also associated with the development of retinopathy. No relation was found with smoking or obesity. Glycaemic control and alcohol consumption were therefore the only aetiologically relevant associations identified. The development of severe retinopathy (exudative and proliferative) showed a particular association with heavy alcohol consumption, occurring in nine of the 70 heavy drinkers
\end{abstract} (13\%) compared with $10(4.4 \%)$ of the rest.

Alcohol consumption may be an important independent factor associated predictively with sight threatening diabetic retinopathy.

\section{Introduction}

Diabetic retinopathy remains a major cause of blindness. Various factors have been suggested as associated with retinopathy in cross sectional studies. A relation between duration of diabetes and the development of retinopathy has long been

\footnotetext{
Diabetic Department, Royal Infirmary, Edinburgh, and Department of Medical Statistics, University of Edinburgh

R J YOUNG, MRCP, senior registrar

D K MCCULLOCH, MRCP, registrar

R J PRESCOTT, PHD, senior lecturer

B F CLARKE, FRCPED, consultant physician
}

Correspondence to: Dr R J Young, Diabetic Department, Royal Infirmary, Edinburgh EH3 9YW. recognised, ${ }^{1}$ and mean clinic blood glucose concentrations are reported to be higher, particularly in severe retinopathy. ${ }^{2} 3$ Published data related to other factors such as cigarette smoking, ${ }^{4-7}$ obesity,,$^{2-11}$ blood pressure, ${ }^{8-18}$ and genetic susceptibility ${ }^{19-21}$ have produced conflicting conclusions well summarised by Dornan et al. ${ }^{3}$

Only two studies have examined prospectively clinical features predictive of retinopathy. Pirart confirmed the effect of duration of diabetes and substantiated the importance of glycaemic control, but a vast drop out rate limited the value of his study. ${ }^{2}$ In Pima Indians, who have a high prevalence of type II (non-insulin-dependent) diabetes, severity of disease, a raised plasma glucose concentration, proteinuria, neuropathy, and systolic blood pressure all had some predictive value. ${ }^{18}$

Much therefore remains uncertain about the factors responsible for the remarkable differences commonly observed between individual diabetics with respect to both the presence and severity of retinopathy. A prospective study of diabetic impotence in a large number of diabetic men ${ }^{22}$ allowed us also to consider clinical features which might be predictive of diabetic retinopathy.

\section{Patients and methods}

At the outset 541 men aged 20-59 years were studied; 101 had been selected at random from the total male clinic population of the same age range and it was shown that the study group was fully representative of the male diabetic clinic population. ${ }^{22}$ During the period of follow up 36 patients left the area and a further 22 became untraceable. In addition, six patients refused reinterview and 11 were unsuitable (five severe psychiatric illness, three severe cerebrovascular disease, one traumatic brain damage, two not diabetic). Of the remaining 466 men, 63 had died leaving 403 who were re-examined. The mean interval between the first and second study examinations was 4 years 8 months (range 3 years 8 months to 6 years 2 months). The same detailed questionnaire was completed at the initial and follow up visits. Age, body weight, duration of diabetes, form of treatment, other drug treatment, smoking (cigarettes a day), and alcohol intake (measures a week) were recorded. In the analysis alcohol intake was divided simply into none to moderate $(\leqslant 10$ pints $(5 \cdot 71)$ of beer or equivalent a week) and heavy ( $>10$ pints of beer or equivalent a week). Direct inquiry elicited past medical history, symptoms of ischaemic heart disease, peripheral vascular disease, sexual function, and diabetic peripheral and autonomic neuropathy. Initially the six most recent clinic blood glucose values were averaged as an index of 
glycaemic control, and at review all of the values obtained during the intervening period were averaged. Retinopathy was assessed by direct ophthalmoscopy of both fundi through dilated pupils in a dark cubicle; findings were recorded as normal (grade 1), microaneurysms with or without dot haemorrhages (grade 2), soft or hard exudates (grade 3), and neovascularisation (grade 4). Proteinuria (Albustix) was recorded as $0, \pm,+,++$, or +++ .

Statistical analysis was principally by the application of linear logistic models. ${ }^{23}$ For binary responses (for example, retinopathy/no retinopathy) these models are the equivalent of the more familiar multiple regression models, ${ }^{24}$ which can be used only for continuous response variables (for example, weight). Thus the linear logistic model allows the simultaneous assessment of the possible influence of several interrelated variables on the development of retinopathy. Two tailed likelihood ratio tests were employed to determine the significance of individual terms. The analysis had two stages. In the first stage only variables relating to the initial examination were the review period. The only significant features then were original alcohol intake $(p=0.02)$, original impotence $(p=0.03)$, and proteinuria at review $(p<0.001)$. The estimated relative risk for heavy drinkers of developing severe retinopathy was 3.5 but the $95 \%$ confidence limits were wide $(1.2$ to 8.4$)$ owing to small numbers.

No other features appeared in the fitted logistic model and, in particular, the other potentially causal factors-smoking and body mass index - did not show any evidence of association with retinopathy even when considered separately.

\section{Discussion}

The prevalence of diabetic retinopathy is about $80 \%$ after 25 years of diabetes in otherwise unselected diabetics, but only a small proportion (roughly 15\%) will have developed prolifera-

TABLE II-Development of retinopathy over 5 years (mean 4 years 8 months; range 3 years 8 months to 6 years 2 months) in 296 diabetic men originally free of retinopathy; significantly associated features. (Percentages given in parentheses)

\begin{tabular}{|c|c|c|c|c|c|c|c|c|c|}
\hline & & \multicolumn{6}{|c|}{ Grade of retinopathy at review } & \multirow{2}{*}{ Total: all groups } & \multirow{2}{*}{ Significance* } \\
\hline & & 1 & 2 & 3 & 3 & & 4 & & \\
\hline \multicolumn{10}{|c|}{ Initial features } \\
\hline Duration of diabetes (years) & $\begin{array}{c}\leqslant 4 \\
5-9 \\
\geqslant 10\end{array}$ & $\begin{array}{r}137(91) \\
59(71) \\
34(55)\end{array}$ & $\begin{array}{r}9(6) \\
14(17) \\
24(39)\end{array}$ & $\begin{array}{l}2 \\
5 \\
3\end{array}$ & $\begin{array}{l}(1) \\
(6) \\
(5)\end{array}$ & $\left.\begin{array}{l}3 \\
5 \\
1\end{array}\right\}$ & $\begin{array}{l}(2) \\
(6) \\
(2)\end{array}$ & $\begin{array}{r}151 \\
83 \\
62\end{array}$ & $\mathrm{p}<0.0001$ \\
\hline Glycaemic control $(\mathrm{mmol} / \mathrm{l}) \dagger$ & $\begin{array}{l}<9 \\
9-14 \\
>14\end{array}$ & $\begin{array}{r}107(87) \\
88(73) \\
41(69)\end{array}$ & $\begin{array}{l}12(10) \\
21(17) \\
14(24)\end{array}$ & $\left.\begin{array}{l}3 \\
6 \\
1\end{array}\right\}$ & $\begin{array}{l}(3) \\
\text { (5) } \\
(2)\end{array}$ & $\begin{array}{l}0 \\
6 \\
3\end{array}$ & $\begin{array}{l}(5) \\
(5)\end{array}$ & $\begin{array}{r}116 \\
121 \\
59\end{array}$ & $p=0.02$ \\
\hline Sexual function & $\begin{array}{l}\text { Potent } \\
\text { Impotent }\end{array}$ & $\begin{array}{r}185(83) \\
45(62)\end{array}$ & $\begin{array}{l}28(13) \\
19(26)\end{array}$ & $\begin{array}{l}7 \\
3\end{array}$ & $\begin{array}{l}(3) \\
(4)\end{array}$ & $\begin{array}{l}3 \\
6\end{array}$ & $\begin{array}{l}(1) \\
(8)\end{array}$ & $\begin{array}{r}223 \\
73\end{array}$ & $\mathrm{p}<0.001$ \\
\hline Alcohol intake (measures/week) & $\begin{array}{l}\$ 10 \\
>10\end{array}$ & $\begin{array}{r}181(80) \\
49(70)\end{array}$ & $\begin{array}{l}35(15) \\
12(17)\end{array}$ & $\begin{array}{l}5 \\
5\end{array}$ & $\begin{array}{l}(2) \\
(7)\end{array}$ & $\begin{array}{l}5 \\
4\end{array}$ & $\begin{array}{l}(2) \\
(6)\end{array}$ & $\begin{array}{r}226 \\
70\end{array}$ & $p=0.02$ \\
\hline \multicolumn{10}{|c|}{ Features at review } \\
\hline Glycaemic control (mmol/l) $\dagger$ & $\begin{array}{l}<9 \\
9-14 \\
>14\end{array}$ & $\begin{array}{r}61(87) \\
127(80) \\
25(57)\end{array}$ & $\begin{array}{r}5(7) \\
21(13) \\
14(32)\end{array}$ & $\left.\begin{array}{l}3 \\
5 \\
2\end{array}\right\}$ & $\begin{array}{l}(4) \\
(3) \\
(5)\end{array}$ & $\begin{array}{l}1 \\
5 \\
3\end{array}$ & $\begin{array}{l}(1) \\
(3) \\
(7)\end{array}$ & $\begin{array}{r}70 \\
158 \\
44\end{array}$ & $\mathrm{p}<0.001$ \\
\hline Proteinuria & $\begin{array}{l}\text { Nil or intermittent } \\
\text { Persistent }\end{array}$ & $\begin{array}{r}224(81) \\
6(30)\end{array}$ & $\begin{array}{r}41(15) \\
6(30)\end{array}$ & $\mathbf{6}$ & (2) & & $\begin{array}{l}(2) \\
(20)\end{array}$ & $\begin{array}{r}276 \\
20\end{array}$ & $\mathrm{p}<0.001$ \\
\hline
\end{tabular}

* Based on likelihood ratio tests from linear logistic model.

Values are means of clinic blood glucose concentrations as detailed in text; 24 records missing at review. Conversion: SI to traditional units-Glucose: $1 \mathrm{mmol} / 1 \approx 18 \mathrm{mg} / 100 \mathrm{ml}$.

included in the model. In the second stage the significant variables from the first stage were retained in the model and the additional effect of variables relating to the follow up period were assessed.

TABLE I-Progression of retinopathy over 5 years (mean 4 years 8 months; range 3 years 8 months to 6 years 2 months) in 403 diabetic men

\begin{tabular}{|c|c|c|c|c|c|}
\hline \multirow{2}{*}{ Initial grade* } & \multirow{2}{*}{ No of patients } & \multicolumn{4}{|c|}{ Grade* at review } \\
\hline & & 1 & 2 & 3 & 4 \\
\hline $\begin{array}{l}1 \\
2 \\
3 \\
4\end{array}$ & $\begin{array}{r}296 \\
66 \\
23 \\
18\end{array}$ & $\begin{array}{r}230 \\
16\end{array}$ & $\begin{array}{r}47 \\
31 \\
3\end{array}$ & $\begin{array}{r}10 \\
6 \\
7\end{array}$ & $\begin{array}{r}9 \\
13 \\
13 \\
18\end{array}$ \\
\hline Total & 403 & 246 & 81 & 23 & 53 \\
\hline
\end{tabular}

*1 $1=$ No retinopathy. $2=$ Microaneurysms \pm haemorrhages 3 = Exudates. $4=$ Neovascularisation.

\section{Results}

Table I shows the fundoscopic findings initially and at review in the 403 men who were followed up. Initially no retinopathy was seen in 296, of whom 66 subsequently developed retinal changes. Table II lists the features significantly associated with the development of retinopathy in this group. From the logistic model the estimated relative risk of developing retinopathy of any grade in "heavy" compared with "none to moderate" drinkers was 2.25 with $95 \%$ confidence limits of $1 \cdot 15$ to $4 \cdot 42$. Table II also suggests that heavy drinkers were more likely to develop severe retinopathy. This was confirmed when the data were analysed to extract features associated with progression of retinopathy from grade 1 to grade 3 or 4 during tive retinopathy or maculopathy. ${ }^{25}$ In clinical practice it is noticeable that in apparently similar patients retinopathy develops to greatly varying degrees. Thus, although sight threatening retinopathy will usually not develop unless there is hyperglycaemia of substantial duration, glycaemic control and duration of diabetes often seem insufficient in themselves to. account for the variations observed. Numerous studies have therefore sought aetiopathogenic factors other than glycaemic control, including genetic susceptibility, body mass index, blood pressure, and smoking, for all of which the evidence is conflicting. We have investigated the influence of some of these factors and additionally, for the first time, the effect of alcohol.

Before discussing the results further it is important to consider the following. Unlike cross sectional studies, prospective studies such as ours may identify predictive as well as coexistent features with respect to a dependent variable such as retinopathy. They cannot, however, determine whether such associations are causal. Nevertheless, based on what we know about the disease the statistically significant and non-significant features in the analysis may be divided into those such as glycaemic control and alcohol consumption which might have an aetiological role in retinopathy and those such as impotence and proteinuria which are probably just other manifestations of generalised microangiopathy. It is the former with which this study was concerned particularly, and the statistical analysis ensured that inclusion of the latter in the model did not obscure or create any significant associations with the former. Finally, almost all prospective studies have the inevitable shortcoming that follow up is incomplete. In our series $14 \%$ of the original cohort were "lost" and $12 \%$ died. We have no evidence that those who moved away or became untraceable differed ap- 
preciably from the group reviewed. With respect to death it might be argued that risk factors for retinopathy may be obscured if they also increase the risk of early death. Features at the outset significantly associated with death during the review period were proteinuria, previous myocardial infarction, symptomatic autonomic neuropathy, and retinopathy. ${ }^{22}$ There was therefore an underrepresentation of initially retinopathy free men among those who died, but none of the features predictive of death are probable aetiological factors for retinopathy, and so it is unlikely that this would influence the results.

Apart from duration of diabetes our prospective study in men initially clinically free of retinopathy showed significant relations between the development of retinopathy of any grade and two features of potential aetiological relevance-glycaemic control and alcohol intake. Body mass index and smoking were included in the analysis but no relation was found; this agrees with other studies. ${ }^{2}+1021$ We did not look for a genetic influence or an association with blood pressure.

The importance of the degree of glycaemic control in the development and progression of diabetic retinopathy remains controversial. There are very few prospective data from which the role of glycaemic control in the development of retinopathy may be deduced, but both Pirart's study and the six year prospective study of Pima Indians found positive associations. ${ }^{2} 10$ Retrospective studies have found a relation between the mean of many clinic blood glucose estimations and the degree of resulting retinopathy. ${ }^{321}$ On the other hand, in intervention studies data relating the degree of glycaemic control to the progression of established retinopathy have produced contradictory results. ${ }^{26} 27$ Our prospective data on clinical retinopathy arising as a new complication support the contention that glycaemic control is an important determinant of the development of retinopathy despite the poor index of glycaemic control used. Thus both initially and during follow up there were significant associations of the degrees of glycaemic control with the development of retinopathy of any grade. Inspection of the data also suggests that severe retinopathy was more likely to develop if glycaemic control was poor during follow up. This was not, however, statistically significant.

The surprising finding was the relation between alcohol intake initially and the subsequent development of retinopathy. So far as we know no such relation has been reported. It is clearly a relatively small effect, but none the less significant, and the particular association with the more severe degrees of retinopathy is noteworthy. If this were a causal relation it might account, in a few diabetics, for otherwise inexplicably rapid progression to sight threatening retinopathy. If we speculate further, potential causal mechanisms might operate via synergistic glucose and alcohol mediated metabolic tissue damage or through the intermediary of hypertension. Alternatively, high alcohol intake might just be a marker for some other habitpossibly poor diet-which is the true causal association.

Whatever the explanation we have shown prospectively the association of two potentially aetiologically explanatory variables - glycaemic control and alcohol intake-with both the development and the progress of diabetic retinopathy. Further primary intervention studies are required to determine the precise degrees of influence and mechanisms of action of these factors.

\section{References}

' Caird FI, Pirie A, Ramsell TG. Diabetes and the eye. Oxford: Blackwell, 1969:30-1,72-7,85,88-91.

2 Pirart J. Diabetes mellitus and its degenerative complications. A prospective study of 4,400 patients observed between 1947 and 1973. Diabetes Care 1978;1:168-88.

${ }^{3}$ Dornan T, Mann JI, Turner R. Factors protective against retinopathy in insulin-dependent diabetics free of retinopathy for 30 years. $\mathrm{Br} \mathrm{Med} \mathcal{F}$ $1982 ; 285$ : 1073-7.

${ }^{4}$ Christiansen JS. Cigarette smoking and prevalence of microangiopathy in juvenile-onset insulin-dependent diabetes mellitus. Diabetes Care $1978 ; 1: 146-9$.
Paetkau ME, Boyd TAS, Winship B, Grace M. Cigarette smoking and diabetic retinopathy. Diabetes $1977 ; 26: 46-9$.

${ }^{6}$ Neilsen MM, Hjollund E. Smoking and diabetic microangiopathy. Lancet 1978;ii:533-4.

7 West KM, Erdreich LS, Stoder JA. Absence of a relationship between smoking and diabetic microangiopathy. Diabetes Care 1980;3:250-2.

× Job D, Eschwege E, Tchobroutsky G, Guyot-Argenton C, Aubry J-P, Derot M. Diabetic retinopathy, duration of diabetes and risk factors of atherosclerotic cardiovascular disease. Acta Diabetol Lat 1975;12: $1-8$.

${ }^{9}$ Hunter PR, Heath H, Bloom A. A clinical comparison between diabetics with no retinopathy after 15 years and severe, deteriorating retinopathy. Diabetologia 1977;13:403.

1" Szabo AJ, Stewart AG, Joron GE. Factors associated with increased prevalence of diabetic retinopathy; a clinical survey. Can Med Assoc f 1967;97:286-92.

$"$ Nilsson SE, Nilsson JE, Frostberg N, Emilsson T. The Kristianstad survey. II. Studies in a representative adult diabetic population with special reference to comparison with an adequate control group. Acta Med Scand 1967;469,suppl:1-42.

${ }^{12}$ Keen $\mathrm{H}$. The prevalence of blindness in diabetics. $\mathcal{f} R$ Coll Physicians Lond 1972; 7:50-60.

${ }^{13}$ Adler R, Freedman J, Kuhar N, Gombos GM. Various parameters of diabetic retinopathy among clinic populations. Ann Ophthalmol 1975; $7: 1447-54$

"West KM, Erdreich LJ, Stober JA. A detailed study of risk factors for retinopathy and nephropathy in diabetes. Diabetes 1980;29:501-8.

${ }^{15}$ Kornerup T. Blood pressure and diabetic retinopathy. Acta Ophthalmol (Copenh) 1957;35:163-74.

${ }^{16}$ Balodimos MC, Aiello LM, Gleason RE, Marble A. Retinopathy in mild diabetes of long duration. Arch Ophthalmol 1969;B1:660-6.

${ }^{17}$ Kohner EM, Fraser TR, Joplin GF, Oakley NW. The effect of diabetic control on diabetic retinopathy. In: Goldberg MF, Fine SL, eds. Symposium on the treatment of diabetic retinopathy. Washington, DC: US Government Printing Office, 1968:119-28. (PHS publication No 1890.)

${ }^{18}$ Knowler WC, Bennett $\mathrm{PH}$, Ballintine EJ. Increased incidence of retinopathy in diabetics with elevated blood pressure. N Engl $\mathcal{F}$ Med 1980; $302: 645-50$.

${ }^{19}$ Dornan TL, Ting A, McPherson CK, et al. Genetic susceptibility to the development of retinopathy in insulin-dependent diabetics. Diabetes $1982 ; 31: 226-31$

${ }^{20}$ Pyke DA, Tattersall RB. Diabetic retinopathy in identical twins. Diabetes $1973 ; 22: 613-8$.

${ }^{21}$ Gray RS, Starkey IR, Rainbow S, et al. HLA antigens and other risk factors in the development of retinopathy in type 1 diabetes. $\mathrm{Br} \mathcal{J}$ Ophthalmol $1982 ; 66: 280-5$.

${ }_{22}$ McCulloch DK, Young RJ, Prescott RJ, Campbell IW, Clarke BF. The natural history of impotence in diabetic men. Diabetologia (in press).

${ }^{23}$ Cox DR. The linear logistic model. Analysis of binary data. London: Methuen, 1970:14-29.

${ }^{24}$ Armitage P. Multiple regression and multivariate analysis. Statistical methods in medical research. Oxford: Blackwell, 1971:302-20.

${ }^{25}$ Lestradet H, Papoz L, Hellouin de Menibus CL, et al. Long term study of mortality and vascular complications in juvenile-onset (type 1) diabetes. Diabetes $1981 ; 30: 175-9$.

${ }^{26}$ Job D, Eschwege E, Guyot-Argentor C, Aubrey JP, Tchoubroutsky G. Effect of multiple daily injections on the course of diabetic retinopathy. Diabetes $1976 ; 25: 463-9$.

${ }^{27}$ Lauritzen T, Frost-Larsen K, Larsen H-W, et al. Effect of 1 year of near-normal blood glucose levels on retinopathy in insulin-dependent diabetics. Lancet $1983 ; \mathrm{i}: 200-4$.

(Accepted 31 fanuary 1984)

THE TEETH, AND THEIR MEDICINES-If you will keep your teeth from rotting, or aching, wash your mouth continually every morning with juice of Lemons, and afterwards rub your teeth either with a Sage-leaf, or else with a little Nutmeg in powder; also wash your mouth with a little fair water after meats; for the only way to keep teeth sound, and free from pain, is to keep them clean. To keep Teeth white-Dip a little piece of white cloth in Vinegar of Quinces, and rub your gums with it, for it is of a gallant binding quality, and not only makes the teeth white, but also strengthens the gums, fastens the teeth, and also causeth a sweet breath. To fasten the Teeth-Seethe the roots of Vervain in old Wine, and wash your teeth often with them, and it will fasten them. For the Tooth-ache-Take the inner rind of an Elder-tree, and bruise it, and put thereto a little Pepper, and make it into balls, and hold them between the teeth that ache. (Nicholas Culpeper (1616-54) The Complete Herbal, 1850.) 